\title{
IL-18 gene polymorphism in patients with visceral leishmaniasis in East Azarbaijan, Iran
}

\author{
Ehsan Ahmadpour • Ahad Bazmani • \\ Mohamad Hasan Kohansal • Abdolhasan Kazemi • \\ Zohre Babaloo
}

Received: 23 October 2014/ Accepted: 11 November 2014/Published online: 22 November 2014

(C) Indian Society for Parasitology 2014

\begin{abstract}
Visceral leishmaniasis (VL) is a parasitic disease caused by Leishmania species. According to the important role of cellular immunity against VL, this study was directed to determine the frequency of $-607 \mathrm{~A} / \mathrm{C}$ and $-137 \mathrm{G} / \mathrm{C}$ genotypes on promoter region of interleukin-18 gene. The study groups included 91 patients with confirmed history of VL, 106 healthy seronegative, and 79 healthy seropositive individuals. All three groups were analyzed by amplification refractory mutation system polymerase chain reaction (ARMS-PCR). The highest rate of $-607 / \mathrm{A}$, and $-607 / \mathrm{C}$ alleles was observed in seronegative individuals $(66 / 67 \%)$ and in the patients $(72 / 83 \%)$. Allele frequency of $-607 / \mathrm{C}$ is more than $-607 / \mathrm{A}$ allele in all groups. In position of -137 , frequency of $-137 / \mathrm{G}$ allele in all groups was more than $-137 / C$. Statistical
\end{abstract}

E. Ahmadpour

Toxoplasmosis Research Center, Mazandaran University of Medical Sciences, Sari, Iran

e-mail: ehsanahmadpour@gmail.com

E. Ahmadpour · A. Bazmani ( $\square)$

Infectious and Tropical Diseases Research Center, Tabriz

University of Medical Sciences, Tabriz, Iran

e-mail: bazmany_ahad@yahoo.com

M. H. Kohansal

Department of Medical Parasitology and Mycology, School of Medicine, Zanjan University of Medical Sciences, Zanjan, Iran

A. Kazemi

Drug Applied Research Center, Department of Medical Parasitology and Mycology, Tabriz University of Medical Sciences, Tabriz, Iran

Z. Babaloo

Immunology Research Center, Tabriz University of Medical

Sciences, Tabriz, Iran analysis of distribution of genotypes, did not reveal any significant difference among groups. On the basis of the results, there was no significant association between VL and polymorphism of IL-18 promoter. The results of this study showed that IL-18 gene promoter polymorphisms at positions -607 and -137 are not associated with VL in East Azerbaijan, Iran.

Keywords Interleukin-18 - Visceral leishmaniasis . ARMS-PCR · East Azerbaijan · Iran

\section{Introduction}

Visceral leishmaniasis (VL) is a parasitic disease caused by protozoan parasites of the Leishmania genus. Leishmania species are responsible for different clinical manifestations in humans, particularly in children and immunocompromised patients. The majority of VL cases are caused by $L$. infantum in the Mediterranean littoral and the Middle East region, also in Iran (Desjeux 2004). VL is endemic in some areas of Iran such as East Azarbaijan, Ardabil and Fars province, but in most places has been seen as sporadic (Mohebali 2013; Oshaghi et al. 2009). These parasites live in the macrophages and reticuloendothelial system. The immunity against Leishmania increases by cellular immune responses, and $\mathrm{T}$ helper cells play a significant role in host resistance against the disease (Vanloubbeeck and Jones 2004). Cytokines such as IFN- $\gamma$, IL-18 and IL-12 will stimulate Th1-type cellular immune response against infection. In VL, development of disease or control of the infection depends on the effectiveness of IFN $\gamma$-induced by innate and adaptive cellular immune responses. It is generally accepted that IFN- $\gamma$ is essential for control and protection of Leishmania infections. From several 
important antileishmanial cytokines, IFN- $\gamma$ plays a particularly prominent macrophage-activating role which extends to the preparing of macrophages to secrete leishmanicidal molecules. IFN- $\gamma$ activates the macrophages to kill the parasites (Nakanishi et al. 2001; Vanloubbeeck and Jones 2004).

IL-18 was initially known as a stimulating factor in IFNproduction $\gamma$. IL-18 is a proinflammatory cytokine of IL-1 cytokines super family and regulates innate and acquired immune responses. The IL-18 and IL-2 acts as a potent cofactor for the expression of Th2 cytokines from NK and T cells (Reddy 2004; Vanloubbeeck and Jones 2004). IL18 role was found more specific in the treatment of mice infected with Leishmania major (Wei et al., 2004).

Single nucleotide mutations occurred in genes that encoding of the IL-18 gene function and blood concentration of this cytokine has been studied in various diseases. For example in Behçet's disease, gene polymorphism of IL-18 and Th1-mediated immune activation is related to disease establishment and severity of the disease (Lee et al., 2006). According to the significant role of IL-18 in protection against VL and identified effect of IL-18 gene polymorphisms on its production, the aim of this study was to check the possible relation between IL-18 gene polymorphism and patients susceptibility to VL.

\section{Materials and methods}

This study was evaluated on 91 patients with confirmed history of VL, 106 healthy seronegative and 79 healthy seropositive individuals. Patients (first group) with VL were diagnosed by clinical symptoms and serological tests. Using the immunofluorescence antibody test (IFAT) on the healthy individual's (with no history of VL) groupings were done. Based on levels of antibody in the serums, individuals were divided into seronegative and seropositive groups. After obtaining informed consent from adult patients or their parents (regarding children), 1-2 $\mathrm{ml}$ of blood were collected in aseptic condition from individuals living in endemic areas of the disease (Ahar, Kaleibar, Osko) in the East Azarbaijan province.

DNA was extracted from all of the blood samples using the salting out method (Miller et al. 1988). Then, using amplification refractory mutation system polymerase chain reaction (ARMS-PCR), individuals genotypes were identified at position $607 \mathrm{~A} / \mathrm{C}$ and $137 \mathrm{G} / \mathrm{C}$. For single nucleotide mutations in the interleukin 18 promoters in both positions 137 and 607, eight primers (Bioneer, Korea) were used with four primers for each of the positions (Table 1).

Reactions were carried out in $0.2 \mathrm{ml}$ microtubes and the final volume was $25 \mu \mathrm{l}$ include: $0.2 \mathrm{mM}$ dNTP, $0.8 \mathrm{pM}$ common reverse primer and forward primer, $0.3 \mathrm{pM}$ internal control primer, $0.6 \mathrm{mM} \mathrm{MgCl} 2,1$ unit TaqDNA polymerase, $10 \mu \mathrm{l} 10 \times$ buffer and $0.3 \mu \mathrm{g}$ genomic DNA. PCR was performed by a thermocycler set under the following thermal conditions: for 137 position, a denaturation step for $2 \mathrm{~min}$ at $94{ }^{\circ} \mathrm{C}$ followed by five cycles of a denaturation for $20 \mathrm{~s}$ at $94{ }^{\circ} \mathrm{C}$, annealing for $40 \mathrm{~s}$ at $64{ }^{\circ} \mathrm{C}$, extension for $70 \mathrm{~s}$ at $72{ }^{\circ} \mathrm{C}$ and then followed by 25 cycles of a denaturation for $20 \mathrm{~s}$ at $94{ }^{\circ} \mathrm{C}$, annealing for $40 \mathrm{~s}$ at $57^{\circ} \mathrm{C}$ and extension for $40 \mathrm{~s}$ at $72{ }^{\circ} \mathrm{C}$ and finally an extension step for $3 \mathrm{~min}$ at $72{ }^{\circ} \mathrm{C}$.

For 607 position, a denaturation step for $2 \mathrm{~min}$ at $94{ }^{\circ} \mathrm{C}$ followed by seven cycles of a denaturation for $20 \mathrm{~s}$ at $94^{\circ} \mathrm{C}$, annealing for $30 \mathrm{~s}$ at $64{ }^{\circ} \mathrm{C}$ and extension for $80 \mathrm{~s}$ at $72{ }^{\circ} \mathrm{C}$ and then followed by 25 cycles of a denaturation for $20 \mathrm{~s}$ at $94{ }^{\circ} \mathrm{C}$, annealing for $40 \mathrm{~s}$ at $57{ }^{\circ} \mathrm{C}$ and extension for $50 \mathrm{~s}$ at $72{ }^{\circ} \mathrm{C}$ and finally an extension step for $3 \mathrm{~min}$ at $72{ }^{\circ} \mathrm{C}$.

Amplification products were analyzed by electrophoresis in $2 \%$ agarose gels and detected by staining with ethidium bromide. The obtained data using SPSS software version 14 and Chi square test were analyzed and a probability value of less than 0.05 was considered significant.

\section{Results}

Frequency of alleles and genotypes in both positions -137 and -607 are shown in Table 2. Length of PCR products

Table 1 Nucleotide sequences of ARMS-PCR primers used for the analysis of IL-18 promoter nucleotide polymorphisms

\begin{tabular}{ll}
\hline Name of primers & Nucleotide sequence of primers \\
\hline Common reverses 137 & AGGAGGGCAAAATGCACTGG \\
Forward $137 / \mathrm{G}$ & CCCCAACTTTTACGGAAGAAAAG \\
Forward $137 / \mathrm{C}$ & CCCCAACTTTTACGGAAGAAAA $\underline{\mathrm{C}}$ \\
Control Forward 137 & CCAATAGGACTGATTATTCCGCA \\
Common reverses 607 & TAACCTCATTCAGGACTTCC \\
Forward 607/C & GTTGCAGAAAGTGTAAAAATTATTAC \\
Forward 607/A & GTTGCAGAAAGTGTAAAAATTATTA \\
Control Forward 607 & CTTTGCTATCATTCCAGGAA \\
\hline
\end{tabular}


Table 2 Frequency of alleles and genotypes in both the -137 and -607 in the IL-18 promoter

\begin{tabular}{|c|c|c|c|c|c|c|c|c|}
\hline Genotype & Patients & Patient group (\%) & Negative serum & Negative serum $(\%)$ & Positive serum & $\begin{array}{l}\text { Positive serum } \\
(\%)\end{array}$ & Total & $\begin{array}{l}\text { Total } \\
(\%)\end{array}$ \\
\hline $607 \mathrm{AC}$ & 31 & 34.07 & 39 & 37.14 & 22 & 28.2 & 92 & 33.57 \\
\hline $607 \mathrm{AA}$ & 25 & 27.47 & 31 & 29.52 & 28 & 35.9 & 84 & 30.66 \\
\hline $607 \mathrm{CC}$ & 35 & 38.46 & 35 & 33.34 & 28 & 35.9 & 98 & 35.77 \\
\hline $137 \mathrm{CG}$ & 22 & 24.18 & 28 & 26.92 & 24 & 29.63 & 74 & 26.81 \\
\hline $137 \mathrm{CC}$ & 10 & 10.99 & 8 & 7.69 & 9 & 11.11 & 27 & 9.78 \\
\hline $137 \mathrm{GG}$ & 59 & 64.83 & 68 & 65.39 & 48 & 59.26 & 175 & 63.41 \\
\hline \multicolumn{9}{|l|}{$137 / 607$} \\
\hline $\mathrm{AC} / \mathrm{CG}$ & 12 & 13.33 & 13 & 12.62 & 11 & 14.48 & 36 & 13.38 \\
\hline $\mathrm{AC} / \mathrm{CC}$ & 1 & 1.11 & 2 & 1.94 & 0 & 0 & 3 & 1.12 \\
\hline $\mathrm{AC} / \mathrm{GG}$ & 17 & 18.89 & 24 & 23.3 & 11 & 14.48 & 52 & 19.33 \\
\hline $\mathrm{AA} / \mathrm{CG}$ & 8 & 8.89 & 11 & 10.68 & 11 & 14.48 & 30 & 11.15 \\
\hline $\mathrm{AA} / \mathrm{CC}$ & 9 & 10 & 3 & 2.91 & 9 & 11.84 & 21 & 7.81 \\
\hline AA/GG & 8 & 8.89 & 15 & 14.57 & 8 & 10.52 & 31 & 11.52 \\
\hline $\mathrm{CC} / \mathrm{CG}$ & 2 & 2.23 & 3 & 2.91 & 2 & 2.63 & 7 & 2.6 \\
\hline $\mathrm{CC} / \mathrm{CC}$ & 0 & 0 & 3 & 2.91 & 0 & 0 & 3 & 1.12 \\
\hline $\mathrm{CC} / \mathrm{GG}$ & 33 & 36.66 & 29 & 28.16 & 24 & 31.57 & 86 & 31.97 \\
\hline \multicolumn{9}{|l|}{ Allele } \\
\hline 607/A & 56 & 45.53 & 70 & 48.61 & 50 & 49.5 & 176 & 47.83 \\
\hline $607 \mathrm{C}$ & 67 & 54.47 & 74 & 51.39 & 51 & 50.5 & 192 & 52.17 \\
\hline $137 / \mathrm{C}$ & 32 & 28.32 & 36 & 27.27 & 33 & 31.13 & 101 & 28.77 \\
\hline $137 / \mathrm{G}$ & 81 & 71.68 & 96 & 72.73 & 73 & 68.87 & 250 & 71.23 \\
\hline
\end{tabular}

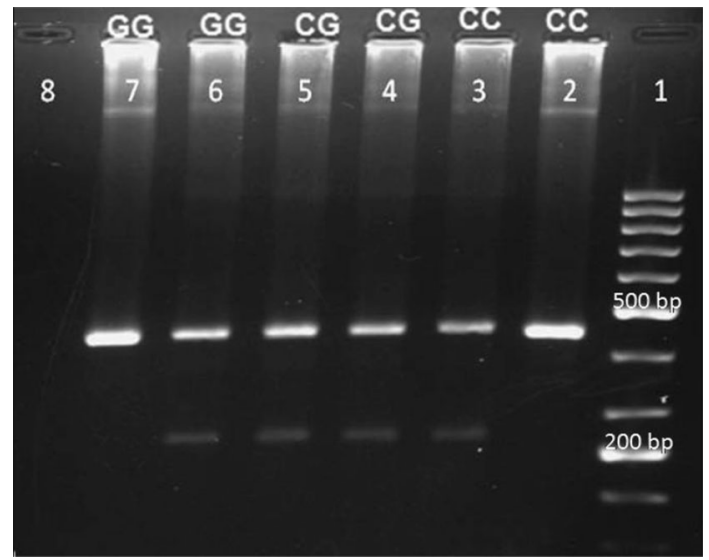

Fig. 1 The electrophoretic patterns of IL-18 gene polymorphisms in 137C/G: Lane 1 (Ladder), Lane 2,3 homozygous CC genotype and 6,7 homozygous GG genotype that PCR product were seen with one of the primers, Lane 4,5 heterozygous CG genotype that PCR products were seen in both primers. Lane 8 (Negative control), length of internal control and target gene were $446 \mathrm{bp}$ and 261, respectively

obtained in the -137 and -607 with the primers and under the conditions of temperature and time was 261 and $136 \mathrm{bp}$, respectively; as well as length of pieces used as internal control was 446 and $301 \mathrm{bp}$. The electrophoretic patterns of IL-18 gene polymorphism are shown in Figs. 1 and 2 .

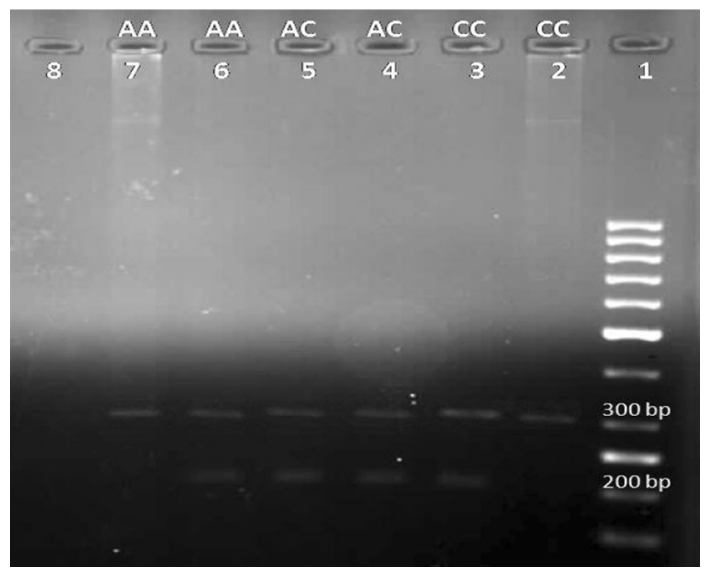

Fig. 2 The electrophoretic patterns of IL-18 gene polymorphisms in 607A/C. Lane 1 (Ladder), Lane 2,3 homozygous CC genotype and 6,7 homozygous AA genotype that PCR product were seen with one of the primers, Lane 4,5 heterozygous AC genotype that PCR products were seen in both primers. Lane 8 (Negative control), length of internal control and target gene were $301 \mathrm{bp}$ and 136, respectively

According to Table 1, alleles frequency of $607 / \mathrm{C}$ is more than allele 607/A in all groups. In position of 137 allele, frequency of $137 / \mathrm{G}$ allele in all groups was more than of $137 / \mathrm{C}$. In -607 position of Il-18 promoter AC, alleles in seronegative individuals (37.14 \%), AA alleles in 
seropositive individuals $(35.9 \%)$ and $607 \mathrm{CC}$ alleles in patients $(38.46 \%)$ were the highest frequency. In comparison with other genotypes, 137 GG genotype was the most common genotype observed among all three groups. Totally, the most genotype observed in study population was $607 \mathrm{CC} / 137 \mathrm{GG}(31.97 \%)$. Both $607 \mathrm{CC} / 137 \mathrm{CC}$ and $607 \mathrm{AC} / 137 \mathrm{CC}$ genotypes with the $1.21 \%$ of all genotypes obtained the lowest available genotype. Statistical analysis of distribution of genotypes did not reveal any significant difference among groups.

\section{Discussion}

Leishmania is an intracellular protozoan parasite that progression of disease in the host depends on the host's cellular immune response. Also resistance to infection was performed by Th1 cells. Recovery and protection against re-infection of Leishmania associated with TCD4 cell count and secreted cytokines (Hajilooi et al. 2014; Hamidi et al. 2013; Vanloubbeeck and Jones 2004). IL-18 is one of the effective cytokines for the control of Leishmania infection and known as a stimulating factor of IFN- $\gamma$ production that plays a significant role in immune responses (Reddy 2004; Sacks and Noben-Trauth 2002). Single nucleotide polymorphisms (SNP) on the gene encoding IL18 , function and blood concentrations of this cytokine have been studied on various diseases. The modified nucleotides of IL-18 gene in promoter region manifest the subsequent changes in the rate of synthesis of IFN- $\gamma$ and IL-18 production. The role of IL-18 on some other parasitic diseases such as malaria, and toxoplasmosis are also investigated (Cai et al. 2000; Kojima et al. 2004). In our study the highest observed genotype in all studied groups was $607 \mathrm{CC} / 137 \mathrm{GG}$ but their frequency varied in patients $(36.66 \%)$, seronegative $(28.16 \%)$, and seropositive $(31.57 \%)$. In the present study, the most and the least frequency of $607 \mathrm{AC} / 137 \mathrm{GG}$ genotype were seen in seronegative $(23.3 \%)$ and seropositive $(14.4 \%)$ groups, respectively. Frequencies of $607 \mathrm{AA} / 137 \mathrm{CC}$ genotypes were similar in two groups of patients and seronegative, but in the seronegative group this rate was lower than the other groups, and seen about 7-9\% difference.

Mullen et al, have been studied the role of IL-18 in Leishmania donovani infection on mice. The results showed little difference in early development of infection between the wild mice and mice with lack of IL-18. But 40-44 days after infection, the role of IL-18 was clear, so that the parasites in the spleen, liver, bone, and brain in mice with lack of IL-18 were more than the control group (wild animals). Naeimi et al. (2006) in their study on polymorphisms of IL-18 in patients with spontaneous abortions and women who had normal vaginal delivery (control group) observed that the $\mathrm{G}$ allele at position -137 (73-75\%) was higher than $\mathrm{C}$ allele. In another study which was conducted on polymorphisms of IL-18 in tuberculosis by Harishankar et al, (2007) it was observed that the $\mathrm{G}$ allele frequency at position $-137(77 \%)$ was more than $\mathrm{C}$ allele. Leung et al, (2006) could not provide any indication to assist the possible role of IL-18 gene polymorphisms in the progress of gastric intestinal metaplasia in Chinese population infected with Pylori. Fallah and Bazmani (2008) showed high frequency of 128Arg allele in healthy group and suggested a possible significant role of soluble E-selectin levels in the inflammatory process in VL.

In conclusion, the majority of patients in -607 positions of interleukin-18 gene were with the homozygous C/C while the majority of healthy people had the heterozygous A/C. It may be associated with a different expression of this gene and its effect on the cellular immune system. Thus carriers have higher resistance against infection with VL but genotypes and allele frequencies showed no significant differences between total study groups.

Acknowledgments This project was supported by a grant from the Infectious and Tropical Diseases Research Center, Tabriz University of Medical Sciences.

Conflict of interests The authors declare that there is no conflict of interests.

\section{References}

Cai G, Kastelein R, Hunter CA (2000) Interleukin-18 (IL-18) enhances innate IL-12-mediated resistance to Toxoplasma gondii. Infect Immun 68(12):6932-6938

Desjeux P (2004) Leishmaniasis: current situation and new perspectives. Comp Immunol Microbiol Infect Dis 27(5):305-318

Fallah M, Bazmani A (2008) Association between endothelial selectin (E-Selectin) gene polymorphisms and E-selectin level with visceral leishmaniais, in an ARMS-PCR based study. Iran $\mathbf{J}$ Parasitol 3(4):23-31

Hajilooi M et al (2014) Is the polymorphism at position -1082 of IL10 gene associated with visceral leishmaniasis? Iran J Public Health 43(8):1107-1112

Hamidi M, Hajilooei M, Bazmani A (2013) Association of transforming growth factor- $\hat{I}^{2} 1$ gene polymorphism with visceral leishmaniasis in an Iranian population. Shiraz E Med J 14(2):123-129

Harishankar M, Selvaraj P, Rajeswari DN, Anand SP, Narayanan PR (2007) Promoter polymorphism of IL-18 gene in pulmonary tuberculosis in South Indian population. Int $\mathrm{J}$ Immunogenet 34(5):317-320

Kojima S, Nagamine Y, Hayano M, Looareesuwan S, Nakanishi K (2004) A potential role of interleukin 18 in severe falciparum malaria. Acta Trop 89(3):279-284

Lee YJ et al (2006) Interleukin-18 promoter polymorphisms in patients with Behcet, s disease. Hum Immunol 67(10):812-818

Leung WK et al (2006) H. pylori genotypes and cytokine gene polymorphisms influence the development of gastric intestinal 
metaplasia in a Chinese population. Am J Gastroenterol 101(4):714-720

Miller SA, Dykes DD, Polesky HF (1988) A simple salting out procedure for extracting DNA from human nucleated cells. Nucleic Acids Res 16(3):1215

Mohebali M (2013) Visceral leishmaniasis in Iran: review of the epidemiological and clinical features. Iran J Parasitol 8(3):348

Naeimi S, Ghiam AF, Mojtahedi Z, Dehaghani AS, Amani D, Ghaderi A (2006) Interleukin-18 gene promoter polymorphisms and recurrent spontaneous abortion. Eur J Obstet Gynecol Reprod Biol 128(1):5-9

Nakanishi K, Yoshimoto T, Tsutsui H, Okamura H (2001) Interleukin-18 regulates both Th1 and Th2 responses. Annu Rev Immunol 19(1):423-474

Oshaghi MA et al (2009) Vector incrimination of sand flies in the most important visceral leishmaniasis focus in Iran. Am J Trop Med Hyg 81(4):572-577
Reddy P (2004) Interleukin-18: recent advances. Curr Opin Hematol 11(6):405-410

Sacks D, Noben-Trauth N (2002) The immunology of susceptibility and resistance to Leishmania major in mice. Nat Rev Immunol 2(11):845-858

Vanloubbeeck Y, Jones DE (2004) The immunology of Leishmania infection and the implications for vaccine development. Ann N Y Acad Sci 1:267-272

Wei X-Q, Niedbala W, Xu D, Luo Z-X, Pollock KGJ, Brewer JM (2004) Host genetic background determines whether IL-18 deficiency results in increased susceptibility or resistance to murine Leishmania major infection. Immunol Lett 94(1):35-37 